\title{
The Heidelberg Sports Activity Score - A New Instrument to Evaluate Sports Activity
}

\author{
J.B. Seeger ${ }^{*}, 1$, S. Weinmann ${ }^{2}$, H. Schmitt ${ }^{3}$, T. Bruckner ${ }^{4}$, M. Krueger ${ }^{2}$ and M. Clarius ${ }^{5}$ \\ ${ }^{I}$ Department of Orthopaedics and Orthopaedic Surgery, University Hospital Giessen and Marburg (UKGM), \\ Klinikstraße 33, 35392 Giessen, Germany \\ ${ }^{2}$ Department of Orthopaedics, Traumatology and Paraplegiology, Heidelberg University Hospital, Schlierbacher \\ Landstrasse 200a, 69118 Heidelberg, Germany \\ ${ }^{3}$ ATOS Klinik Heidelberg, Bismarckplatz 9-15, 69115 Heidelberg, Germany \\ ${ }^{4}$ Institute of Medical Biometry and Informatics, University of Heidelberg, Im Neuenheimer Feld 305, 69120 Heidelberg, \\ Germany \\ ${ }^{5}$ Department of Orthopaedic and Trauma Surgery, Vulpius Klinik GmbH, Vulpiusstraße 29, 74906 Bad Rappenau, \\ Germany
}

\begin{abstract}
Objective: An appropriate measuring instrument for assessing if sports activity changes after a surgical treatment is not available yet. We hypothesised that the Heidelberg Sport Activity Score is a valid and adequate instrument for measuring sport activity in patients before and after operative treatment.

Design: This retrospective study presents a new score (Heidelberg Sports Activity Score - HAS) for measuring the sport activity in 11 selected sports. Validity, sensitivity and test-retest-reliability have been assessed.

Setting: The score includes importance of the sports for patients, impairment of the corresponding joint, and frequency and duration of the sporting activities undertaken. The HAS was validated using 3 criteria: external validation, internal comparison of groups and correlation with the Tegner Score.

Patients: A total of 655 patients were recruited for this study. The inclusion criterion was a planned or already received reconstruction (such as a high tibial osteotomy or implantation of a hip or knee prosthesis). The sport activity of these patients was evaluated before and after treatment.
\end{abstract}

Main Outcome Measurement: The mean HAS was 32.1 points preoperatively and 37.0 postoperatively $(\mathrm{p}=0.017)$.

Results: A high correlation was found between the HAS and the Tegner Score (TS) $(\mathrm{r}=0.729 ; \mathrm{p}=0.010)$. The Test-RetestReliability was performed within a time interval of 2 weeks and a significant correlation of $r=0.752$ was found $(\mathrm{p}<0.01)$. Sensitivity was analysed using a sample of patients before and after high tibial osteotomy.

Conclusions: The HAS is a new, easy to use, effective and valid measuring instrument for the assessment of sports activity in patients before and after operative treatment.

Keywords: Sports activity, activity score, medial osteoarthritis, high tibial osteotomy.

\section{INTRODUCTION}

For many people, sport constitutes a vital part of subjective well being. If degenerative joint diseases cause pain and immobilising limitation of function and movement then sport activity is usually no longer possible. A frequently asked question is whether the sporting ability can be restored or even improved in treatments such as high tibial osteotomy or implantation of a prosthesis [1-4]. This question has only been answered to a limited extent in the literature [5]. This is partly due to the lack of applicable measuring instruments to quantitatively determine sport activity.

*Address correspondence to this author at the Department of Orthopaedics and Orthopaedic Surgery, University Hospital Giessen and Marburg, Klinikstrasse 33, D-35392 Giessen, Germany; Tel: +49-641-985-42616; Fax:+49-641-985-42629; E-mail: joern.seeger@uk-gm.de
Sport activity is usually measured with the Tegner Score (TS) [6], first introduced in 1985, or the UCLA Score [7]. Both are based on a simple and fast grading system with 11 and 10 categories respectively.

Patients are classified according to their activity level between 0 (Tegner Score) and 10 for the Tegner Score (TS) and 1 and 10 for the UCLA Score. A value of 0 in the TS and 1 in the UCLA Score stands for immobility. Continuous participation in contact sports (UCLA Score) or competitive sports such as soccer - in a national and international elite (Tegner Score) are assigned a value of 10.

The Tegner Score was originally developed for the evaluation of knee ligament injuries. However due to its practicability it is also used for other joints [8]. In this study a newly developed sport activity score will be presented (see 
APPENDIX). The purpose of the study was to evaluate a newly developed sport activity score in comparison to the Tegner Score before and after joint reconstruction. We hypothesised that the Heidelberg Sport Activity Score is a valid and adequate instrument for measuring sport activity in patients before and after operative treatment.

\section{MATERIAL AND METHODS}

\section{Ethics}

The following study was approved by the institutional university review board, accepted by the local ethics committee and complies with the principles laid down in the Declaration of Helsinki in 2004 (ISO 9001: 2000).

\section{Development of a New Sport Activity Score}

A total of 655 patients were recruited from the Orthopaedic University Hospital in Heidelberg, Germany. They had been planned for or had already received a reconstruction (such as a high tibial osteotomy or implantation of a hip or knee prosthesis). The sport activity of these patients was evaluated before and after treatment.

The ten sports or sport groups (walking, swimming, cycling, running, cross-country skiing, alpine skiing, golfing, dancing, racket sports (tennis, squash, badminton etc.) and ball sports (handball, soccer, volleyball etc.)) most frequently mentioned by the patients were identified for use in the score. Marginal sports or less mentioned sports were included as a miscellaneous, and eleventh, category. Some of the sports included in the instrument are also recommended for patients with endoprostheses by the German Association for Sports Medicine and Prevention (DGSP).

A total of 10 sport medicine specialists from different fields such as internal medicine, pneumology, orthopaedics, et cetera were consulted regarding their assessment of a sports activity score. They were all supervising athletes, had experience as a team doctor and examined the athletes in degrees of fitness at least twice a week. All of these specialists stated that the elements frequency and duration of the assessed sport had to be included in the instrument for a quantitative statement about sports activity to be made. Furthermore, an activity score published by Weiss et al. states that the factors impairment of sport exercise of the analysed joint and the importance for the patient should be included as well [9].

All factors of the new score were divided into 4 different categories. The frequency was rated between 0 (not exercised) and 5 (four times a week). The duration of each sport was graded between 0 (not exercised) and 5 (longer than 3 hours). The level of importance $(0=$ not important; 5 $=$ extremely important) and the grade of impairment of the assessed joint $(0=$ very impaired; $5=$ not impaired $)$ were specified for each sport. According to Weiss et al. (2002) this $0-5$ grading scale proved to be practicable in the knee function score [9].

For the factors mentioned the following formula was generated:

(frequency + duration) $x(1+$ impairment/10 + importance/10)
From this it follows that a score value between 0 and 20 points could be achieved for each sport.

Example calculation "walking":

A patient walks once a week with a duration of between $2-3$ hours. He is scarcely impaired by the operated knee joint and the sport is extremely important for him:

walking: $(3+4) \times(1+4 / 10+5 / 10)=13.3$

The values of each single sport are added to an overall activity score (HAS). This means that for 11 sports investigated values of between 0 and 220 could be achieved, as with a maximum value of 20 points for each sport an overall value of 220 points would be realised.

All sports not undertaken were graded with a 0 . The questionnaire took about 120 minutes to complete.

\section{Validity}

The score was validated by means of an internal comparison of four groups using Spearman's rank correlation. The groups were 61 patients with medial osteoarthritis of the knee joint (from the Orthopaedic University Hospital Heidelberg) a control group of 60 probands with healthy knee joints (city of Heidelberg and surrounding area) a group of 20 competitive swimmers and 20 triathletes, both groups recruited from the Olympic Training Center and participating in nationwide tournaments.

The HAS was correlated with the frequently used Tegner Score in the overall group and in each separate group (Spearman's rank correlation). As proposed in the study of Tegner et al., an external classification was performed by one sport medicine specialist [6].

\section{Reliability}

The test-retest-reliability of the score was tested with Spearman's rank correlation. Therefore, half of the control group (30 probands) answered the questionnaire twice with a defined time interval of 4 weeks to rule out any bias of memorisation.

\section{Sensitivity}

To evaluate the sensitivity of the score, 61 patients were questioned regarding their sport activity preoperatively and 1-4 years after high tibial osteotomy due to medial osteoarthritis of the knee joint. The sensitivity was statistically verified using the Wilcoxon signed rank test in SPSS $^{\circledR}$ version 16.0 for Windows (SPSS Inc. Chicago, USA).

\section{RESULTS}

Validity

Table 1 shows the results of the internal group comparison (Fig. 1). For the overall group, the HAS showed a higher correlation than the TS with a correlation coefficient of $\mathrm{r}=0.811(\mathrm{p}=0.001)$.

\section{Reliability}

The test-retest-reliability showed a value of $r=0.752$. This correlation is significant $(p<0.01)$ (Table 2 ). 
Table 1. Results of the Internal Group Comparison

\begin{tabular}{|c|c|c|c|c|}
\hline $\mathbf{n}=$ & $\begin{array}{c}\text { Patients with } \\
\text { Knee Pain }\end{array}$ & $\begin{array}{c}\text { Control } \\
\text { Group }\end{array}$ & Swimmers & Triathletes \\
\hline \hline Female & 22 & 60 & 20 & 20 \\
\hline Male & 39 & 35 & 12 & 10 \\
\hline age (mean) & 48.6 & 37.2 & 17.3 & 22.3 \\
\hline HAS (mean) & 32.1 & 38.5 & 44.4 & 59.3 \\
\hline SD & 20.2 & 17.8 & 14.2 & 17.7 \\
\hline min - max & $3.4-89.5$ & $15.3-71.0$ & $14.3-71.5$ & $32.6-94.6$ \\
\hline Tegner (mean) & 4.7 & 4.7 & 5.3 & 6.9 \\
\hline SD & 1.3 & 1.3 & 1.3 & 0.7 \\
\hline min - max & $2-7$ & $3-7$ & $3-7$ & $6-8$ \\
\hline $\begin{array}{c}\text { Correlation } \\
\text { HAS - TS }\end{array}$ & 0.729 & 0.875 & 0.876 & 0.821 \\
\hline p-value & 0.001 & 0.001 & 0.001 & 0.001 \\
\hline
\end{tabular}

Table 2. Test-Retest-Reliability

\begin{tabular}{|c|c|c|}
\hline & HAS & 4-Week Control \\
\hline \hline $\mathbf{n}=$ & 30 & 30 \\
\hline mean & 37.0 & 36.7 \\
\hline SD & 20.7 & 18.4 \\
\hline min - max & $0.0-94.0$ & $0.0-94.0$ \\
\hline correlation & \multicolumn{2}{|c|}{$r=0.752$} \\
\hline p-value & \multicolumn{2}{|c|}{0.010} \\
\hline
\end{tabular}

\section{Sensitivity}

The HAS showed a mean of 32.1 points preoperatively and 37.0 postoperatively. This difference was significant $(\mathrm{p}=0.017)$. Preoperatively the TS had a mean of 4.7 and postoperatively 4.6. This difference was not significant with $\mathrm{p}=0.818$ (Table 3).

Table 3. HAS and Tegner Score Pre- and Postoperative

\begin{tabular}{|c|c|c|c|c|}
\hline & $\begin{array}{c}\text { HAS } \\
\text { Pre-Op }\end{array}$ & $\begin{array}{c}\text { HAS } \\
\text { Post-Op }\end{array}$ & $\begin{array}{c}\text { Tegner } \\
\text { Pre-Op }\end{array}$ & $\begin{array}{c}\text { Tegner } \\
\text { Post-Op }\end{array}$ \\
\hline \hline $\mathbf{n}=$ & 61 & 61 & 61 & 61 \\
\hline mean & 32.1 & 37.0 & 4.7 & 4.6 \\
\hline SD & 20.2 & 20.7 & 1.3 & 1.3 \\
\hline min - max & $3.4-89.5$ & $0.0-94.0$ & $2-7$ & $2-7$ \\
\hline p-value & \multicolumn{3}{|c|}{0.017} & \multicolumn{2}{c|}{0.818} \\
\hline
\end{tabular}

\section{DISCUSSION}

To date sport activity has been evaluated using the published Tegner Score (TS). The grading is performed using a numerical scale from 0 to 10 based on the activity or sport performed and whether the sport is a recreational exercise or competitive sport.

Without doubt this score is easy to evaluate. Even though it was developed for the observation of knee ligament injuries, it can be translated to other joints and injuries as well [6].

The sensitivity is limited, especially in the follow-up due to a broad graduation into categories [10]. Our data reveal a moderate sensitivity of the TS in the follow-up of patients' sports activity after high tibial osteotomy due to medial osteoarthritis of the knee joint.

Besides the frequency, the HAS also includes the duration of the exercise of each single sport and therefore, unlike the TS, a quantitative statement can be made.

In the HAS a total of 10 sports were considered, which after our survey represent a cross-section of the current sports in patients with joint diseases as described in literature [11]. Furthermore, each patient had the opportunity to add a previously unmentioned sport in the category "miscellaneous" so that as many sports as possible could be included.

The HAS has been developed to measure sports activity in patients with joint diseases. The sports activity depends on the impairment of the disease. For the patients, the importance of the exercise also plays a significant role in their satisfaction [9]. These two factors were therefore included in the score in addition to duration and frequency (in line with Weiss et al. [9]). The factor importance allows conclusions to be drawn about a patient's motivation, the impairment on pain and functional disability. Weiss et al. could state that the importance of the sport exercise correlates with the frequency with which it is performed [9]. This implies that if the surgical treatment is successful, patients can perform what seems to be important for them irrespective of whether they are impaired by their joint disease or not.

\section{Validity}

According to Healy et al. the validity of a new score can be confirmed with the help of different methods of validation [1]. External validation can be performed by a board of experts or against a gold standard score [12].

Our results show a high correlation between the HAS and the TS. However, the TS was developed specifically for sports putting stress on the knee joint. Soccer players playing at a national or international level would generate the highest value of 10, irrespective of other sport activities. However, a triathlete, who swims, runs and performs cycling over a long distance could only achieve a value of 8 in the Tegner Score. The TS therefore favours some sports more than others.

The score used should, however, examine the sport activity of patients with joint diseases before and after treatment. We chose our weighting, so that the versatile sportspeople can generate the highest values. Moreover, the HAS has been validated by comparing internal groups. As expected, in patients with joint diseases the lowest values were observed, whereas triathletes in the highest class also showed the highest values in the HAS. 


\section{Reliability}

Tegner et al. describe a test-retest reliability with a correlation coefficient of $\mathrm{r}=0.97$ for the $\mathrm{TS}$, although 15 patients were classified twice by one surgeon with an interval of two weeks [6].

Our results present a test-retest reliability for the HAS of $r=0.752$ after 2 weeks. The time span was chosen in order to rule out the bias of memorisation. However, within this period of time the sports activity, impairment and importance could have changed.

\section{Sensitivity}

The HAS showed a significant change of sports activity in our patients. Furthermore, the score had a good sensitivity whereas the TS showed a change from 4.7 to 4.6. This antidromic tendency can be explained by the fact that our patients included soccer players who were ranked high in the TS. At the time of follow-up, they gave up this sport to pursue a different one. That is why the TS declines whereas the HAS could increase due to other exercised sports.

Basically, a score should fulfil three requirements [10, $13,14]$. It should measure what it claims to measure (validity), deliver reliable and reproducible results (reliability) and changes should be detected (sensitivity). The HAS fulfils these guidelines.

Like other scores that are generated subjectively with a questionnaire, the HAS certainly does have limitations and is liable to the common influencing factors of subjective data acquisition. However, the score allows the sport activity to be measured in a simple and cheap manner so that the presented score can also easily be used for follow-up.

\section{Perspective}

The HAS showed a mean of 32.1 points preoperatively and 37.0 postoperatively. This signifies that patients are more active concerning sports after high tibial osteotomy. In addition, the newly developed sport activity score is an effective and valid instrument for measuring sport activity before and after operative treatment.

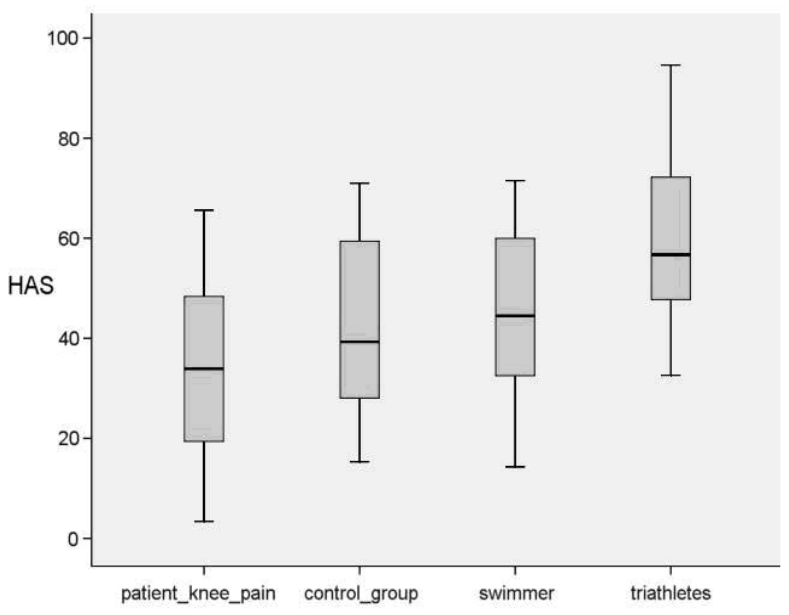

Fig. (1). Box plot of internal group comparison of the Heidelberg Sport Activity Score in patients with knee pain, control group, swimmers and triathletes.

\section{CONFLICT OF INTEREST}

The authors have no proprietary, financial, professional or other personal interest of any nature or kind in any product, service and/or company that could be construed as influencing the results and views presented in this article.

\section{ACKNOWLEDGEMENTS}

No direct or indirect benefits in any form have been received or will be received from a commercial party with respect to this study.

\section{APPENDIX}

\section{Heidelberg Sports Activity Questionnaire}

\begin{tabular}{|c|c|c|c|c|c|}
\hline \multicolumn{6}{|l|}{ Walking } \\
\hline duration & $\begin{array}{l}0 \min \\
{[]}\end{array}$ & $\begin{array}{l}<15 \min \\
{[]}\end{array}$ & $\begin{array}{l}15-60 \mathrm{~min} \\
{[]}\end{array}$ & $\begin{array}{l}\text { 61-120 min } \\
{[]}\end{array}$ & $\begin{array}{lc}121-180 \text { min } & >3 \text { hours } \\
{[]} & {[]}\end{array}$ \\
\hline frequency & $\begin{array}{l}0 \\
{[]}\end{array}$ & $\begin{array}{l}\text { 1x/month } \\
{[]}\end{array}$ & $\begin{array}{l}2 \mathrm{x} / \text { month } \\
{[]}\end{array}$ & $\begin{array}{l}1 \mathrm{x} / \text { week } \\
{[]}\end{array}$ & $\begin{array}{lc}2-3 \mathrm{x} / \text { week } & >4 \mathrm{x} / \text { week } \\
{[]} & {[]}\end{array}$ \\
\hline \multicolumn{3}{|c|}{ How important is this activity for you? } & & $\begin{array}{l}\text { mportant } \\
{[1] \quad[2]}\end{array}$ & $\begin{array}{l}5=\text { extremely important } \\
{[3] \quad[4] \quad[5]}\end{array}$ \\
\hline \multicolumn{3}{|c|}{ Are you impaired by your affected knee joint? } & & $0=$ very impaired & $5=$ not at all \\
\hline
\end{tabular}




\section{Swimming}

duration

\begin{tabular}{|llllll|}
\hline $0 \min$ & $<15 \min$ & $15-60 \mathrm{~min}$ & $61-120 \mathrm{~min}$ & $121-180 \mathrm{~min}$ & $>3$ hours \\
{[]} & {[]} & {[]} & {[]} & {[]} & {[]} \\
\hline
\end{tabular}

frequency

\begin{tabular}{|lllllc|}
\hline 0 & $1 \mathrm{x} /$ month & $2 \mathrm{x} /$ month & $1 \mathrm{x} /$ week & $2-3 \mathrm{x} /$ week & $>4 \mathrm{x} /$ week \\
{[]} & {[]} & {[]} & {[]} & {[]} & {[]} \\
\hline
\end{tabular}

How important is this activity for you?

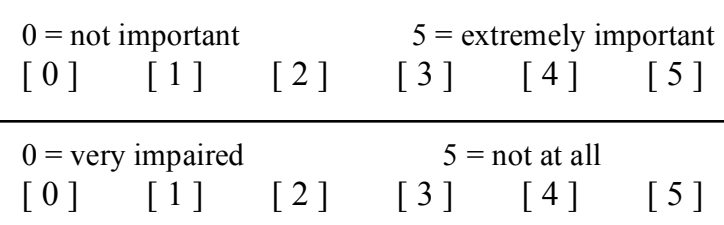

Are you impaired by your affected knee joint?

$\left[\begin{array}{llllll}0] & {[1]} & {[2]} & {[3]} & {[4]} & {[5]}\end{array}\right.$

\section{Cycling}

duration

\begin{tabular}{|lllllc|}
\hline $0 \min$ & $<15 \min$ & $15-60 \mathrm{~min}$ & $61-120 \mathrm{~min}$ & $121-180 \mathrm{~min}$ & $>3$ hours \\
{[]} & {[]} & {[]} & {[]} & {[]} & {[]} \\
\hline
\end{tabular}

frequency

\begin{tabular}{|c|c|c|c|c|}
\hline 0 & 1x/month & $2 \mathrm{x} / \mathrm{month}$ & 1x/week & $2-3 x /$ week \\
\hline [ ] & [ ] & [ ] & [ ] & [ ] \\
\hline
\end{tabular}

How important is this activity for you?

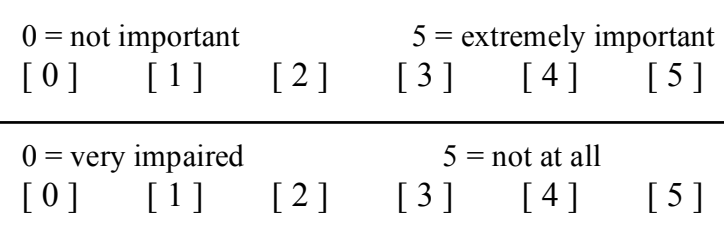

Are you impaired by your affected knee joint?

\section{Running}

duration

\begin{tabular}{|lllllc|}
\hline $\begin{array}{l}0 \min \\
{[]}\end{array}$ & $<15 \min$ & $15-60 \mathrm{~min}$ & $61-120 \mathrm{~min}$ & $121-180 \mathrm{~min}$ & $>3$ hours \\
& {[]} & {[]} & {[]} & {[]} & {[]} \\
\hline
\end{tabular}

frequency

\begin{tabular}{|lllllc|}
\hline 0 & $1 \mathrm{x} /$ month & $2 \mathrm{x} /$ month & $1 \mathrm{x} /$ week & $2-3 \mathrm{x} /$ week & $>4 \mathrm{x} /$ week \\
{[]} & {[]} & {[]} & {[]} & {[]} & {[]} \\
\hline
\end{tabular}

How important is this activity for you?

Are you impaired by your affected knee joint?

\begin{tabular}{|c|c|c|c|c|}
\hline \multicolumn{2}{|l|}{$0=$ not important } & \multicolumn{3}{|c|}{$5=$ extremely important } \\
\hline$[0] \quad[1]$ & [2] & [3] & [4] & [5] \\
\hline $0=$ very $\mathrm{imp}$ & & & & \\
\hline$[0]$ & [2] & [3 ] & [4] & {$[5$} \\
\hline
\end{tabular}


(APPENDIX) contd.....

\section{Cross-Country Skiing}

duration

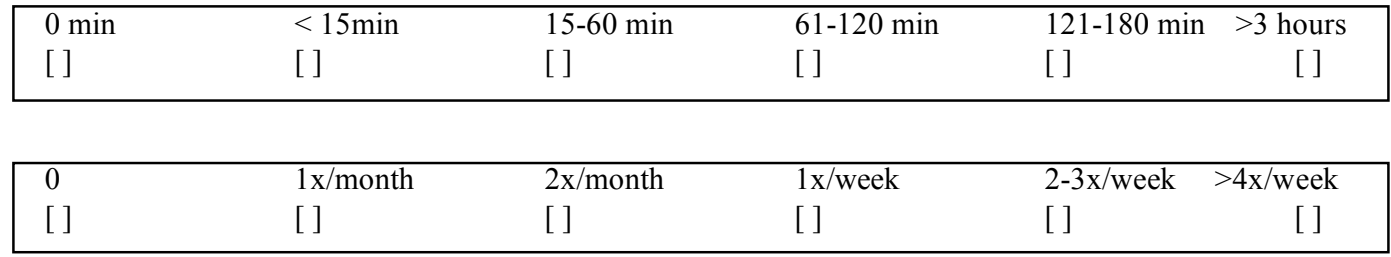

How important is this activity for you?

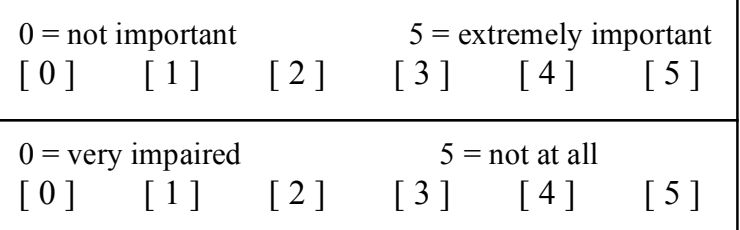

Are you impaired by your affected knee joint?

\section{Alpine Skiing}

duration

\begin{tabular}{|lllllc|}
\hline $\begin{array}{ll}0 \min \\
{[]}\end{array}$ & $<15 \min$ & $15-60 \mathrm{~min}$ & $61-120 \mathrm{~min}$ & $121-180 \mathrm{~min}$ & $>3$ hours \\
{[]} & {[]} & {[]} & {[]} & {[]} \\
\hline 0 & $1 \mathrm{x} /$ month & $2 \mathrm{x} /$ month & $1 \mathrm{x} /$ week & $2-3 \mathrm{x} /$ week & $>4 \mathrm{x} /$ week \\
{[]} & {[]} & {[]} & {[]} & {[]} & {[]} \\
\hline
\end{tabular}

How important is this activity for you?

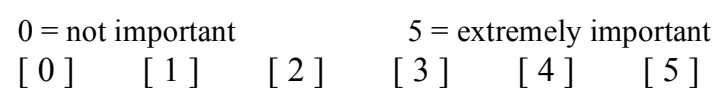

Are you impaired by your affected knee joint?

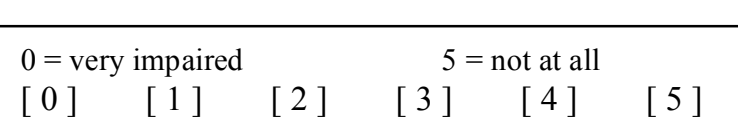

\section{Golf}

duration

\begin{tabular}{|lllllc|}
\hline $\begin{array}{l}0 \min \\
{[]}\end{array}$ & $<15 \min$ & $15-60 \mathrm{~min}$ & $61-120 \mathrm{~min}$ & $121-180 \mathrm{~min}$ & $>3$ hours \\
{[]} & {[]} & {[]} & {[]} & {[]} \\
\hline 0 & $1 \mathrm{x} /$ month & $2 \mathrm{x} /$ month & $1 \mathrm{x} /$ week & $2-3 \mathrm{x} /$ week & $>4 \mathrm{x} /$ week \\
{[]} & {[]} & {[]} & {[]} & {[]} & {[]} \\
\hline
\end{tabular}

How important is this activity for you?

\begin{tabular}{|c|c|c|c|c|}
\hline $0=$ not importan & & \multicolumn{3}{|c|}{$5=$ extremely important } \\
\hline [ 1 ] & [2] & [3] & [4] & {$[5]$} \\
\hline $0=$ very impaire & & & ot at al & \\
\hline [ 1 ] & [2] & [3 ] & [4] & {$[5]$} \\
\hline
\end{tabular}

Are you impaired by your affected knee joint? 


\section{Dancing}

duration

\begin{tabular}{|lllllc|}
\hline $0 \min$ & $<15 \min$ & $15-60 \min$ & $61-120 \min$ & $121-180 \min$ & $>3$ hours \\
{[]} & {[]} & {[]} & {[]} & {[]} & {[]} \\
\hline
\end{tabular}

frequency

\begin{tabular}{|lllllc|}
\hline 0 & $1 \mathrm{x} /$ month & $2 \mathrm{x} /$ month & $1 \mathrm{x} /$ week & $2-3 \mathrm{x} /$ week & $>4 \mathrm{x} /$ week \\
{[]} & {[]} & {[]} & {[]} & {[]} & {[]} \\
\hline
\end{tabular}

How important is this activity for you?

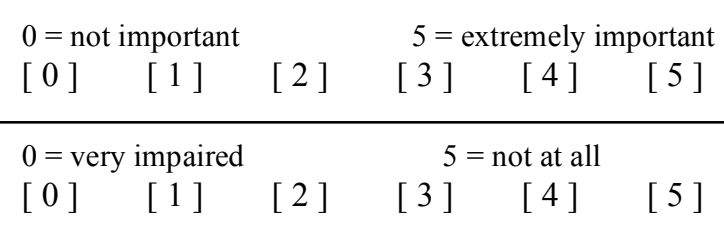

Are you impaired by your affected knee joint?

\section{Racket Sports}

duration

\begin{tabular}{|lllllc|}
\hline $0 \min$ & $<15 \min$ & $15-60 \mathrm{~min}$ & $61-120 \mathrm{~min}$ & $121-180 \mathrm{~min}$ & $>3$ hours \\
{[]} & {[]} & {[]} & {[]} & {[]} & {[]} \\
\hline
\end{tabular}

frequency

\begin{tabular}{|lllllc|}
\hline 0 & $1 \mathrm{x} /$ month & $2 \mathrm{x} /$ month & $1 \mathrm{x} /$ week & $2-3 \mathrm{x} /$ week & $>4 \mathrm{x} /$ week \\
{[]} & {[]} & {[]} & {[]} & {[]} & {[]} \\
\hline
\end{tabular}

How important is this activity for you?

Are you impaired by your affected knee joint?

\begin{tabular}{|c|c|c|c|c|}
\hline \multicolumn{2}{|l|}{$0=$ not important } & \multicolumn{3}{|c|}{$5=$ extremely important } \\
\hline [ 1 ] & [2] & [3] & [ 4] & [5] \\
\hline $0=$ very impaire & & & ot at al & \\
\hline [ 1 ] & [2] & [3 ] & [4] & [5] \\
\hline
\end{tabular}

\section{Ball Games}

duration

\begin{tabular}{|lllllc|}
\hline $\begin{array}{l}0 \min \\
{[]}\end{array}$ & $<15 \min$ & $15-60 \mathrm{~min}$ & $61-120 \mathrm{~min}$ & $121-180 \mathrm{~min}$ & $>3$ hours \\
& {[]} & {[]} & {[]} & {[]} & {[]} \\
\hline
\end{tabular}

frequency

\begin{tabular}{|lllllc|}
\hline 0 & $1 \mathrm{x} /$ month & $2 \mathrm{x} /$ month & $1 \mathrm{x} /$ week & $2-3 \mathrm{x} /$ week & $>4 \mathrm{x} /$ week \\
{[]} & {[]} & {[]} & {[]} & {[]} & {[]} \\
\hline
\end{tabular}

How important is this activity for you?

Are you impaired by your affected knee joint?

\begin{tabular}{|c|c|c|c|}
\hline $0=$ not importan & & $5=$ & remely i \\
\hline [ 1 ] & [2] & [3] & [4] \\
\hline $0=$ very impaire & & & ot at all \\
\hline [1 ] & [2] & [3] & [4 ] \\
\hline
\end{tabular}


(APPENDIX) contd......

\section{Miscellaneous}

duration

\begin{tabular}{|c|c|c|c|c|c|}
\hline $\begin{array}{l}0 \min \\
{[]}\end{array}$ & $\begin{array}{l}<15 \text { min } \\
{[]}\end{array}$ & $\begin{array}{l}15-60 \mathrm{~min} \\
{[]}\end{array}$ & $\begin{array}{l}61-120 \mathrm{~min} \\
{[]}\end{array}$ & $\begin{array}{l}121-180 \mathrm{~min} \\
{[]}\end{array}$ & $\begin{array}{c}>3 \text { hours } \\
{[]}\end{array}$ \\
\hline
\end{tabular}

frequency

\begin{tabular}{|c|c|c|c|c|c|}
\hline 0 & $1 \mathrm{x} /$ month & $2 \mathrm{x} /$ month & 1x/week & $2-3 x /$ week & $>4 \mathrm{x} /$ week \\
\hline [ ] & {[]} & [ ] & [ ] & [ ] & [ ] \\
\hline
\end{tabular}

How important is this activity for you?

Are you impaired by your affected knee joint?

\begin{tabular}{|c|c|c|c|}
\hline \multicolumn{2}{|l|}{$0=$ not important } & \multicolumn{2}{|c|}{$5=$ extremely important } \\
\hline$[0]$ & {$[2]$} & {$[3]$} & {$[5]$} \\
\hline $0=$ very impaired & & $5=$ not at al & \\
\hline$[0]$ & [2] & [3] & {$[5]$} \\
\hline
\end{tabular}

\section{REFERENCES}

[1] Healy WL, Iorio R, Lemos MJ. Athletic activity after joint replacement. Am J Sports Med 2001; 29: 377-88.

[2] Naal FD, Fischer M, Preuss A, et al. Return to sports and recreational activity after unicompartmental knee arthroplasty. Am J Sports Med 2007; 35: 1688-95.

[3] Niemeyer P, von Heyden J, Köstler W, et al. Sportaktivität nach valgisierender Tibiakopfosteotomie in Open-Wedge-Technik mit einem internen Plattenfixateur $\left(\right.$ Tomofix $^{\mathrm{TM}}$ ). Sport Orthop Sport Trauma 2009; 25: 88-95.

[4] Salzmann GM, Ahrens P, Naal FD, et al. Sporting Activity After High Tibial Osteotomy for the Treatment of Medial Compartment Knee Osteoarthritis. Am J Sports Med 2009; 37: 312-8.

[5] Kuster MS, Grob K, Gachter A. Knee endoprosthesis: sports orthopedics possibilities and limitations. Orthopade 2000; 29: 73945.

[6] Tegner Y, Lysholm J. Rating systems in the evaluation of knee ligament injuries. Clin Orthop Relat Res 1985; 198: 43-9.

[7] Amstutz HC, Thomas BJ, Jinnah R, et al. Treatment of primary osteoarthritis of the hip. A comparison of total joint and surface replacement arthroplasty. J Bone Joint Surg Am 1984; 66: 228-41.
[8] Halasi T, Kynsburg A, Tállay A, et al. Development of a new activity score for the evaluation of ankle instability. Am J Sports Med 2004; 32: 899-908.

[9] Weiss JM, Noble PC, Conditt MA, et al. What functional activities are important to patients with knee replacements? Clin Orthop Relat Res 2002; 404: 172-88.

[10] Briggs KK, Kocher MS, Rodkey WG, et al. Reliability, validity, and responsiveness of the Lysholm knee score and Tegner activity scale for patients with meniscal injury of the knee. J Bone Joint Surg Am 2006; 88: 698-705.

[11] Naal FD, Maffiuletti NA, Munzinger U, et al. Sports after hip resurfacing arthroplasty. Am J Sports Med 2007; 35: 705-11.

[12] Marx RG, Stump TJ, Jones EC, et al. Development and evaluation of an activity rating scale for disorders of the knee. Am J Sports Med 2001; 29: 231-18.

[13] Marx RG, Jones EC, Allen AA, et al. Reliability, validity, and responsiveness of four knee outcome scales for athletic patients. J Bone Joint Surg Am 2001; 83: 1459-69.

[14] Saleh KJ, Mulhall KJ, Bershadsky B, et al. Development and validation of a lower-extremity activity scale. Use for patients treated with revision total knee arthroplasty. J Bone Joint Surg Am 2005; 87: 1985-94.

(C) Seeger et al.; Licensee Bentham Open.

This is an open access article licensed under the terms of the Creative Commons Attribution Non-Commercial License (http://creativecommons.org/licenses/by-nc/3.0/) which permits unrestricted, non-commercial use, distribution and reproduction in any medium, provided the work is properly cited. 